\title{
Salt transport in plaster/substrate layers
}

\author{
J. Petković · H. P. Huinink · L. Pel · \\ K. Kopinga $\cdot$ R. P. J. van Hees
}

Received: 19 May 2005/ Accepted: 30 November 2005/Published online: 13 July 2006

(C) RILEM 2006

\begin{abstract}
We have investigated how transport and accumulation of salt in a plaster depends on the underlying masonry material. To this end, moisture and sodium profiles have been measured non-destructively with a Nuclear Magnetic Resonance (NMR) technique during drying of plaster/substrate systems. The same plaster is applied on two substrates of which the pores are either an order of magnitude larger or smaller than those of the plaster. The moisture and salt transport and the salt accumulation differed significantly for these two systems. In a plaster/Bentheimer sandstone system (the pores of the plaster are smaller than those of the substrate) all salt is removed from the substrate and accumulates in the plaster. In a plaster/calcium-silicate brick system (the
\end{abstract}

J. Petković · H. P. Huinink · L. Pel $(\varangle) \cdot$ K. Kopinga Department of Applied Physics,

Eindhoven University of Technology,

P.O. Box 513, 5600 MB Eindhoven, The Netherlands e-mail: L.Pel@tue.nl

R. P. J. van Hees

TNO Building and Construction Research,

Delft University of Technology,

P.O. Box 49, 2600 AA Delft, The Netherlands

R. P. J. van Hees

Delft \& Faculty of Architecture,

Delft University of Technology,

P.O. Box 5043, 2600 GA Delft, The Netherlands substrate has a considerable amount of pores that are smaller than those of the plaster) some salt crystallizes in the plaster layer, but a significant amount of salt remains within the substrate itself. The salt transport from substrate to plaster is quantified in terms of an efficiency number $\varepsilon$, which can be estimated from the pore-size distributions measured by mercury intrusion porosimetry.

Résumé Nous avons étudié de quelle manière le transport et l'accumulation de sel dans du plâtre dépend du matériau de construction sous-jacent. Pour ce faire, les évolutions de l'humidité et de la teneur en sodium ont été mesurées de manière non destructrice à l'aide de la résonance magnétique nucléaire lors du séchage de systèmes plâtre/substrat. Un plâtre identique est appliqué sur deux substrats dont les pores sont un ordre de grandeur plus gros ou plus petits que ceux du plâtre. Le transport de l'humidité et du sel mais aussi l'accumulation du sel diffèrent de manière significative dans chacun de ces deux dispositifs. Dans un système plâtre/grès de Bentheimer (où les pores du plâtre sont plus petits que ceux du substrat), le sel a complètement disparu du substrat et se concentre dans le plâtre. Dans un système plâtre/brique de calcium-silicate (où le substrat possède un nombre significatif de pores qui sont plus petits que ceux du platre), une certaine fraction $d u$ sel cristallise dans la couche de plâtre mais la majeure 
partie demeure localisée au sein du substrat. Le transport du sel du substrat vers le plâtre est quantifié en termes d'efficacité $\varepsilon$. Celle-ci peut être estimée à partir de la distribution des pores suivant leur taille que l'on mesure grâce à de la porosimétrie par intrusion de mercure.

\section{Introduction}

The choice of restoration plasters, suitable for long-time protection and performance, is a delicate conservation problem. The performance of specially developed plasters is not always satisfactory $[1,2]$. The durability of a plaster and its ability to protect the underlying masonry strongly depend on its transport properties with respect to salt and moisture. Although salt damage has been investigated intensively for several decades [3], the mechanisms that control salt crystallization in porous media are poorly understood. A better understanding of the transport of water and dissolved ions during drying and salt crystallization in plasters and the underlying masonry (the substrate) is necessary for understanding salt damage and for developing plasters that meet the requirements with respect to durability and protection.

The fluid transport in a single medium depends on its pore structure [4]. In principle, knowledge about the pore-size distribution, the geometry of the pore network, the connectivity of the pores, and the properties of the pore walls is necessary for understanding the transport behavior, because these properties determine the permeability [5-8], diffusivity $[9,10]$, and capillary pressure $[4,11]$. The pore-size distribution is one of the parameters which determine the material durability. Generally, bricks with large pores seem to be more resistant to damage than bricks with small pores [12-14].

In the existing recommendations for the application of plasters on salt-loaded substrates [15] the influence of the substrate materials is not taken into account. The aim of the work described in this paper is to investigate the influence of a difference in pore-size distribution between the plaster and substrate layer on the water and salt transport and the salt accumulation during drying. Until now, the details of the drying process of two-layer materials has not been investigated very extensively $[16,17]$. Using a Nuclear Magnetic Resonance (NMR) technique we are able to measure non-destructively the time evolution of water and dissolved ions in these layered materials during drying. In section 2 we will discuss some theoretical aspects of the relation between the pore structure and the water and salt transport during drying. The salt transport from the substrate to the plaster will be quantified in terms of an efficiency number. In section 3 the Nuclear Magnetic Resonance (NMR) technique will be explained and the main characteristics of the materials will be given. In section 4 the time evolution of the water and salt distribution during drying will be presented. From these measurements, the efficiency number is calculated. In section 5 we will discuss the salt transport in systems of which the substrate is salt loaded but the plaster layer is saturated with pure water. In this section we will also discuss the salt transport in plaster/substrate combinations of which the pore-size distributions are known from literature. The conclusions are presented in section 6 .

\section{Theory}

A typical experiment is shown schematically in Fig. 1. The plaster/substrate system is isolated on all sides except from the air/plaster interface, where single-sided drying occurs.

Drying of a homogeneous, uniformly wet, non salt-loaded material occurs in two stages: a uniform drying period and a receding drying front period $[18,19]$. During the first period, moisture transport is fast and occurs through the water network. During the period characterized by the receding drying front, water near this drying front is present in the form of isolated clusters, and transport occurs through the vapor phase. The water clusters evaporate because of the large difference in relative humidity between the vapor near the clusters and the air at the drying surface of the material.

During drying air will invade the largest pores, where the capillary pressure $p_{\mathrm{c}}$ is lowest, as can be seen from the following equation $[4,11]$ : 
$p_{\mathrm{c}}=\frac{2 \gamma \cos \phi}{r_{\mathrm{m}}}$,

where $r_{\mathrm{m}}$ is a pore radius that discriminates between the pores filled with water $\left(r<r_{\mathrm{m}}\right)$ and the empty pores $\left(r>r_{\mathrm{m}}\right) \cdot \gamma\left[\mathrm{N} \mathrm{m}^{-1}\right]$ is the surface tension of the liquid/vapor interface and $\phi$ is the contact angle between the liquid/air and liquid/ solid interface.

In two-layer systems the drying is determined by the pore-size distributions of the two materials, as long as the following assumptions are valid:

- the two materials are in perfect hydraulic contact

- the water network is a percolating network

- external pressure gradients are negligible, i.e., drying is completely determined by $p_{\mathrm{c}}$, which is continuous at the interface between the two materials

At a given moisture content, water is present in the pores with diameters smaller than $r_{\mathrm{m}}$ in each material. Therefore, the material with the largest pores is emptied first. In the case of plaster/substrate systems, the plaster will dry first if it has larger pores than the substrate. On the other hand, if the plaster has smaller pores than the substrate, the substrate will dry first, at least in the single-sided drying process sketched in Fig. 1.

Ions are transported both by advection and diffusion. Advection drives the salt in the same direction as the water. During drying, advection will lead to salt accumulation and crystallization at the drying surface. Diffusion is a competitive process which tends to level off concentration differences within the liquid in the sample. The competition between advection and diffusion can be characterized by the Péclet number $P e$, given by:

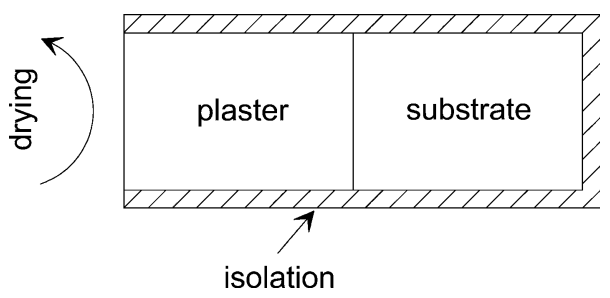

Fig. 1 Plaster/substrate system isolated at all sides except the air/plaster interface, where the water vapor can escape
$P e=\frac{|U| L}{D}$

where $|U|, L$ and $D$ are the water velocity, the length scale of interest, and the ion diffusivity, respectively. For $P e \gg 1$ advection dominates the ion transport, which happens at sufficiently high drying rates, whereas for $P e \ll 1$ diffusion dominates the ion transport, which happens at low drying rates.

In plaster/substrate systems, a plaster, applied on a substrate with larger pores, stays wet during a longer time than the substrate. If the condition $P e \gg 1$ is valid everywhere in the system, advection dominates and salt will be transported and accumulated at the air/plaster interface. If $P e \ll 1$, diffusion dominates and salt will precipitate everywhere in the plaster. If the plaster has larger pores than the substrate, the plaster will dry first. For $P e \gg 1$, salt will be transported to the drying interface, which in this case is not necessarily the air/ plaster interface, but rather the plaster/substrate interface, since the plaster dries first. For $P e \ll 1$, salt will precipitate everywhere in the substrate.

The ion transport from the substrate to the plaster can be characterized by means of a dimensionless efficiency $\varepsilon$ :

$\varepsilon=\frac{|\Delta m|}{m_{0}}$

In this equation $m_{0}$ is the initial mass of the sodium in the substrate and $|\Delta m|$ is the mass of the sodium which is transported from the substrate to the plaster layer at a time $t^{\prime}$ when the top plaster layer has dried out. The efficiency number is easy to estimate, since $m_{0}$ and $|\Delta m|$ are experimentally accessible parameters.

Since salt is transported with water, the efficiency number $\varepsilon$ can be estimated from the water quantities, even without knowing the salt quantities. When $P e \gg 1$, the salt concentration in the sample during drying equals the initial concentration, except in a narrow region just below the drying surface [20]. Therefore, it follows From Eq. 3 that:

$$
\varepsilon \cong \varepsilon_{\mathrm{w}}=\frac{|\Delta V|}{V_{0}}=\frac{|\Delta \Theta|}{\Theta_{0}}
$$


where $\varepsilon_{\mathrm{w}}$ is efficiency number calculated from the water quantity. $\Theta_{0}$ and $V_{0}$ are the initial moisture content and the initial volume of water in the substrate, respectively. $|\Delta \Theta|$ and $|\Delta V|$ are the moisture content and the volume of water that disappeared from the substrate at the time $t^{\prime}$ when the plaster has dried out, respectively.

Since the water transport in a two-layer system is characterized by the pore size differences between the two materials, the efficiency number $\varepsilon$ for the case $P e \gg 1$ can also be estimated from the capillary pressure law (Eq. 1). This estimate will be denoted by $\varepsilon_{\mathrm{p}}$. The volume of water that disappears from the substrate while the plaster completely dries out equals the volume of the pores in the substrate with a radius larger than that of the smallest pores in plaster. Hence $\varepsilon_{\mathrm{p}}$ can be calculated from the total pore volume $V_{\mathrm{p}}$ of the substrate and the volume of the pores $V_{\mathrm{p}}^{\prime}$ in the substrate with a radius larger than that of the smallest pores in the plaster:

$\varepsilon_{\mathrm{p}}=\frac{V_{\mathrm{p}}^{\prime}}{V_{\mathrm{p}}}$

By measuring the cumulative pore volume of both materials as function of pore size with mercury intrusion porosimetry, $\varepsilon_{\mathrm{p}}$ can be calculated and the salt accumulation can be estimated even without investigating the actual transport at all. $\varepsilon_{\mathrm{w}}$ and $\varepsilon_{\mathrm{p}}$ are defined as ideal numbers which are estimated assuming $P e \gg 1$. The situation is less clear when this assumption is not satisfied. In the case of very slow drying $(P e \ll 1)$, diffusion dominates and there is no salt accumulation at the drying surface. During drying the salt concentration will increase uniformly in both materials of the sample from the initial concentration $c_{0}$ to the saturation concentration. If the substrate dries first, the salt concentration will increase faster in the substrate than in the plaster, and dissolved ions will diffuse into the plaster. If the drying process is sufficiently slow, the efficiency number may tend to 1 for low initial salt quantities or if the thickness of the substrate is much smaller than the thickness of the plaster. If, on the other hand, the plaster dries first, dissolved ions may diffuse back to the substrate, which may even reduce the efficiency number to negative values.

\section{Experimental}

Nuclear Magnetic Resonance (NMR) imaging is a non-destructive technique for quantitative mapping of certain chemical elements in materials. Using a home-built NMR scanner, designed for the imaging of the building materials [21, 22], it is possible to follow the distribution of water and dissolved sodium ions in time during wetting [23] or drying [20].

The resonance frequency of a certain type of nucleus, called the Larmor frequency, is determined by the magnitude of the applied magnetic field $B$ :

$v_{\mathrm{i}}=\frac{1}{2 \pi} \gamma_{\mathrm{i}} B$

where the index $\mathrm{i}$ refers to the type of nucleus $(\mathrm{H}$ or $\mathrm{Na}), v_{\mathrm{i}}[\mathrm{Hz}]$ is the Larmor frequency, $\gamma_{\mathrm{i}}$ is the gyromagnetic ratio of the nucleus $\left(\gamma_{\mathrm{H}} / 2 \pi=\right.$ $\left.42.58 \mathrm{MHz} / \mathrm{T} ; \gamma_{\mathrm{Na}} / 2 \pi=11.27 \mathrm{MHz} / \mathrm{T}\right)$ and $B[\mathrm{~T}]$ is the strength of the magnetic field.

When the applied magnetic field is homogeneous, the nuclei in the whole sample are at resonance at the same frequency, and a signal from whole sample is obtained. To achieve spatial resolution it is necessary to excite the nuclei in the limited volume of the sample. This is done by making the resonance frequency position dependent by superimposing a constant magnetic field gradient $G$ on the main magnetic field $B_{0}$ :

$B=B_{0}+G\left(x-x_{0}\right)$

where $x[\mathrm{~m}]$ is a position in the sample along the direction of the magnetic field gradient $G\left[\mathrm{~T} \mathrm{~m}^{-1}\right]$ and $x_{0}$ is the position where $B=B_{0}$.

The NMR signal $S$ is proportional to the density of the nuclei $\rho$ [24]:

$S=C k \rho\left[1-\exp \left(-t_{\mathrm{R}} / T_{1}\right)\right] \exp \left(-t_{\mathrm{E}} / T_{2}\right)$

In this equation $C$ is a calibration factor, $k$ is the sensitivity of nuclei relative to that of hydrogen, $T_{1}$ [s] is the spin-lattice (longitudinal) relaxation time, $t_{\mathrm{R}}[\mathrm{s}]$ is the repetition time of the spin-echo experiment, $T_{2}[\mathrm{~s}]$ is spin-spin (transverse) relaxation time, and $t_{\mathrm{E}}[\mathrm{s}]$ is the spin-echo time. The relaxation times $T_{1}$ and $T_{2}$ are proportional to the 
pore size [25, 26], which enables us to distinguish water present in different pores. To measure the water in the entire pore system, which may include a certain fraction of nuclei with a small $T_{2}, t_{\mathrm{E}}$ has to be as short as possible. In our experiments we have used $t_{\mathrm{E}, \mathrm{H}}=0.2 \mathrm{~ms}$ and $t_{\mathrm{E}, \mathrm{Na}}=0.45 \mathrm{~ms}$.

Nevertheless, we observed some Na signal loss in materials with small pores, due to fast $T_{2}$ relaxation. If quantitative measurements are required, this loss has to be corrected for. Since the NMR sensitivity for $\mathrm{Na}$ is low, the $\mathrm{Na}$ signals from 256 successive spin-echo measurements were averaged to obtain a sufficient signal to noise ratio.

In our experiments the main magnetic field $B_{0}$ and the gradient $G$ were $0.7 \mathrm{~T}$ and $0.33 \mathrm{~T} \mathrm{~m}^{-1}$, respectively. The resulting onedimensional resolution was $0.9 \mathrm{~mm}$ for $\mathrm{H}$ and $3.5 \mathrm{~mm}$ for $\mathrm{Na}$. The sample holder is schematically depicted in Fig. 2. Since the transverse relaxation time of $\mathrm{Na}$ in $\mathrm{NaCl}$ crystals is of the order of $10 \mu \mathrm{s}$ [27], our equipment is only able to measure dissolved $\mathrm{Na}$

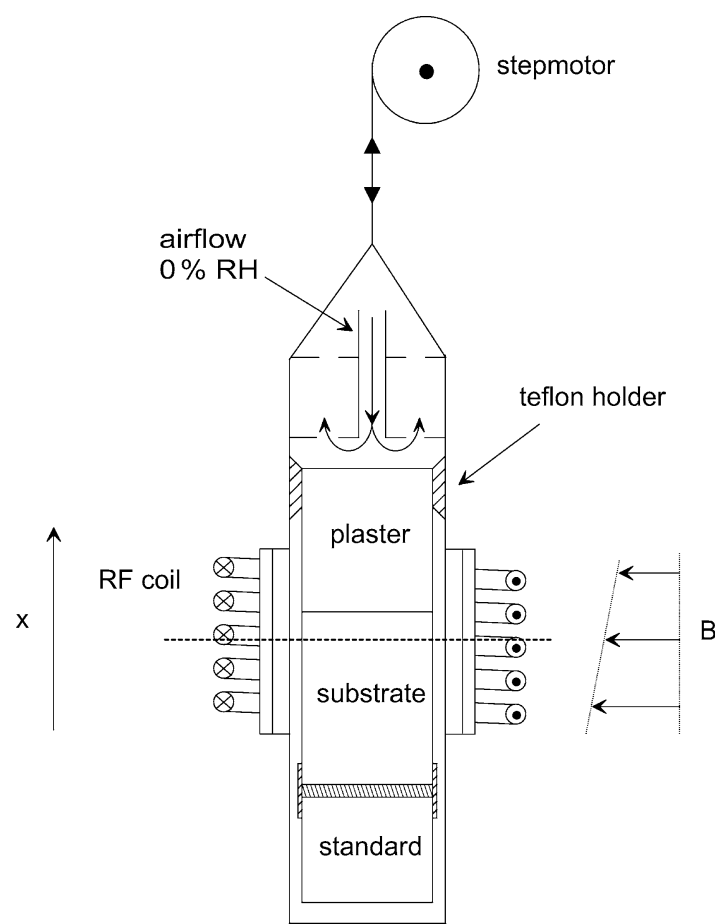

Fig. 2 Set-up for the drying experiments. The teflon holder with the sample and the standard is moved in the vertical direction $(x)$ by means of the step motor. The signal from the $\mathrm{H}$ or $\mathrm{Na}$ nuclei at resonance is received by the RF coil. The air that is blown over the sample has a relative humidity $h_{\mathrm{a}}<0.01$ ions. During the acquisition of the profiles the RF frequency is switched in such a way that the $\mathrm{H}$ and $\mathrm{Na}$ signals can be recorded quasi-simultaneously [23]. $\mathrm{H}$ and $\mathrm{Na}$ signal intensities are related to the corresponding volume of water $\left[\mathrm{cm}^{3}\right]$ and quantity of $\mathrm{Na}$ [mol] using a standard (see Fig. 2). This consisted of an $\mathrm{NaCl}$ solution $\left(c=3 \mathrm{~mol} \mathrm{l}^{-1}\right)$ to which a small amount of $\mathrm{CuCl}_{2}$ $\left(c=0.03 \mathrm{~mol} \mathrm{l}^{-1}\right)$ was added to decrease the $T_{1}$ relaxation time and, correspondingly, the repetition time $t_{\mathrm{R}}$. To determine the $\mathrm{H}$ and $\mathrm{Na}$ profiles over the whole sample and the standard, the sample holder was moved in the vertical $(x)$ direction by means of a step motor. The time to measure both a water and $\mathrm{Na}$ profile within the sample and the standard was about $2 \mathrm{~h}$. Before the actual drying was started, i.e., before the air flow was switched on, a water and a $\mathrm{Na}$ profile were measured that served as $t=0$ reference. The moisture and $\mathrm{Na}$ profiles for $t>0$ were obtained by interpolating the successive experimental profiles measured at different times.

Cylindrical samples were cut with a diameter of $19 \mathrm{~mm}$ and a total length of $50 \mathrm{~mm}$. The plaster/ substrate interface was located more or less in the middle of each sample ( $x=25 \mathrm{smm})$. Initially the samples were uniformly capillary saturated by immersing them in water or a $\mathrm{NaCl}$ solution, $c=4 \mathrm{~mol} \mathrm{l}^{-1}$, for about $20 \mathrm{~h}$. Because of the low NMR sensitivity for $\mathrm{Na}$, a rather high concentration has been chosen. The corresponding salt quantity amounts to roughly $0.02 \mathrm{~g}$ per gram of sample. To be able to model the observed drying and salt transport as $1 \mathrm{D}$ processes, the samples were sealed with teflon tape at all sides except from the top (the plaster/air interface), over which the dry air is blown. The relative humidity of the air was less than $1 \%$ and the air flow was kept at $0.71 \mathrm{~min}^{-1}$. This corresponds to an air speed over the drying surface in the range of $0.03-0.15 \mathrm{~m} / \mathrm{s}$, estimated from the geometry of the NMR set-up.

Experiments were done on two different plaster-substrate systems. Bentheimer sandstone and calcium-silicate brick were used as substrates. The plaster had the same composition in both systems: lime:cement:sand $=4: 1: 10(\mathrm{v} / \mathrm{v})$. Per kg cement in the mixture $3.6 \mathrm{~kg}$ of water was used. The two substrates were selected because of the significant differences in their pore-size distributions. After 
application of the plaster, the systems were kept during 7 days under foil, and next they were kept for 7 days in a controlled environment at $20^{\circ} \mathrm{C}$ and $65 \%$ relative humidity. After that the systems were dried at $40^{\circ} \mathrm{C}$ and carbonated during a few weeks in an environment with $3 \% \mathrm{CO}_{2}(\mathrm{v} / \mathrm{v})$ at $50 \%$ relative humidity. Using phenolphtalein as $\mathrm{pH}$ indicator it was verified that full carbonation had been reached.

The pore sizes and open porosities of the materials have been measured by means of mercury intrusion porosimetry. The cumulative and differential pore volumes vs. pore diameter are presented for both systems in Fig. 3. This figure shows that the pores of the plaster are an order of
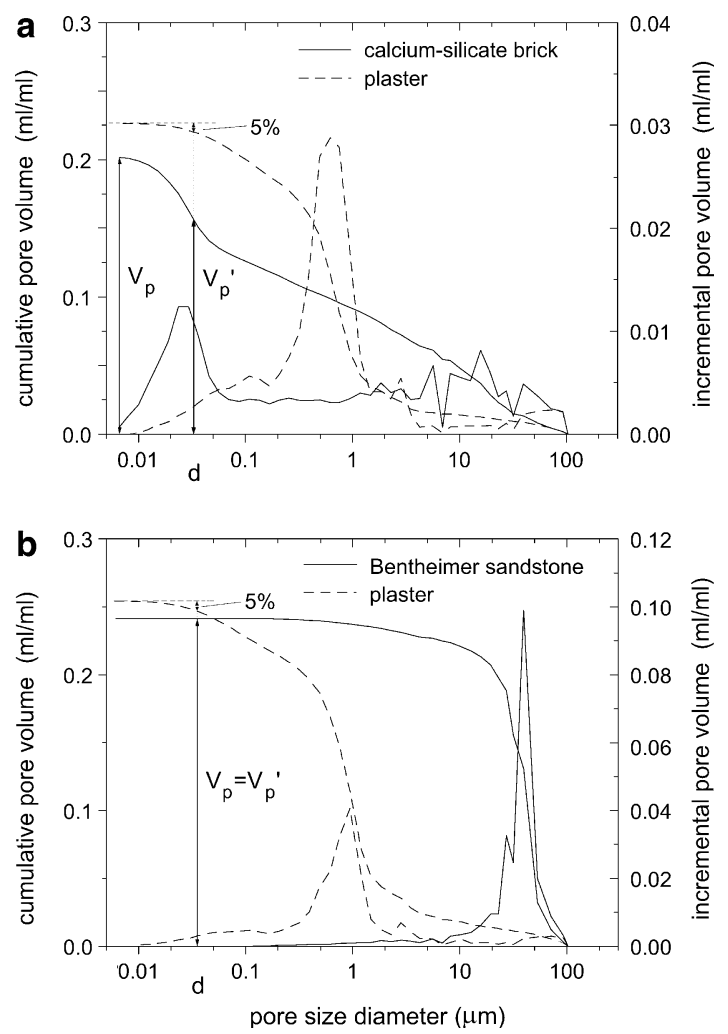

Fig. 3 Pore sizes of (a) plaster and calcium-silicate brick and (b) plaster and Bentheimer sandstone measured by mercury intrusion porosimetry. The efficiency of the salt transport from the substrate to the plaster $\varepsilon_{\mathrm{p}}$ can be estimated from the total pore volume of the substrate $V_{\mathrm{p}}$ and the volume of pores in the substrate $V_{\mathrm{p}}^{\prime}$ with a size larger than the smallest pores in the plaster. The size corresponding to $\mathrm{V}_{\mathrm{p}}^{\prime}$ is taken as the pore size at which the cumulative volume of the smaller pores in the plaster equals $5 \%$ of the total pore volume magnitude smaller than those of Bentheimer sandstone and an order of magnitude larger than the nanometer pores of the calcium-silicate brick. We like to add that the fraction of large pores (10$100 \mu \mathrm{m})$ in, e.g., the calcium-silicate brick may have been underestimated, due to ink-bottle effects. Mercury intrusion porosimetry actually probes the distribution of the pores as a function of the size of the pore entrance, which causes the results to depend on the geometry of the pore system.

\section{Results}

\subsection{Plaster/Bentheimer sandstone}

\subsubsection{Pure water}

First, the drying behavior of plaster/substrate systems saturated with pure water has been studied. In Fig. 4a the water profiles in the plaster/Bentheimer sandstone system are plotted for several times during the drying process. In all systems we have studied, the water evaporates from the sample through the air/plaster interface $(x=4)$. The total amounts of water in the plaster and the Bentheimer sandstone as a function of drying time are presented in Fig. $4 b$.

Two drying stages can be observed. During stage $1(t<2 \mathrm{~h})$ the Bentheimer sandstone dries, whereas the plaster remains saturated. The plaster starts to dry during the second drying stage $(t>2 \mathrm{~h})$. After about $6 \mathrm{~h}$ the water network in the plaster breaks down and a receding drying front enters the plaster. This drying behavior can be understood as follows. During drying water tends to remain in the pores where the capillary pressures $\left(p_{\mathrm{c}}\right)$ is highest, which are the smallest pores according to Eq. 1. The Bentheimer sandstone dries first, because its pores are generally an order of magnitude larger than the pores in the plaster (Fig. 3a).

\subsubsection{Salt solution}

To study the salt transport in the plaster/Bentheimer sandstone system, the sample was initially saturated with a $\mathrm{NaCl}$ solution, $c=4 \mathrm{~mol} \mathrm{l}^{-1}$. In Fig. 5a we have plotted water profiles for several 

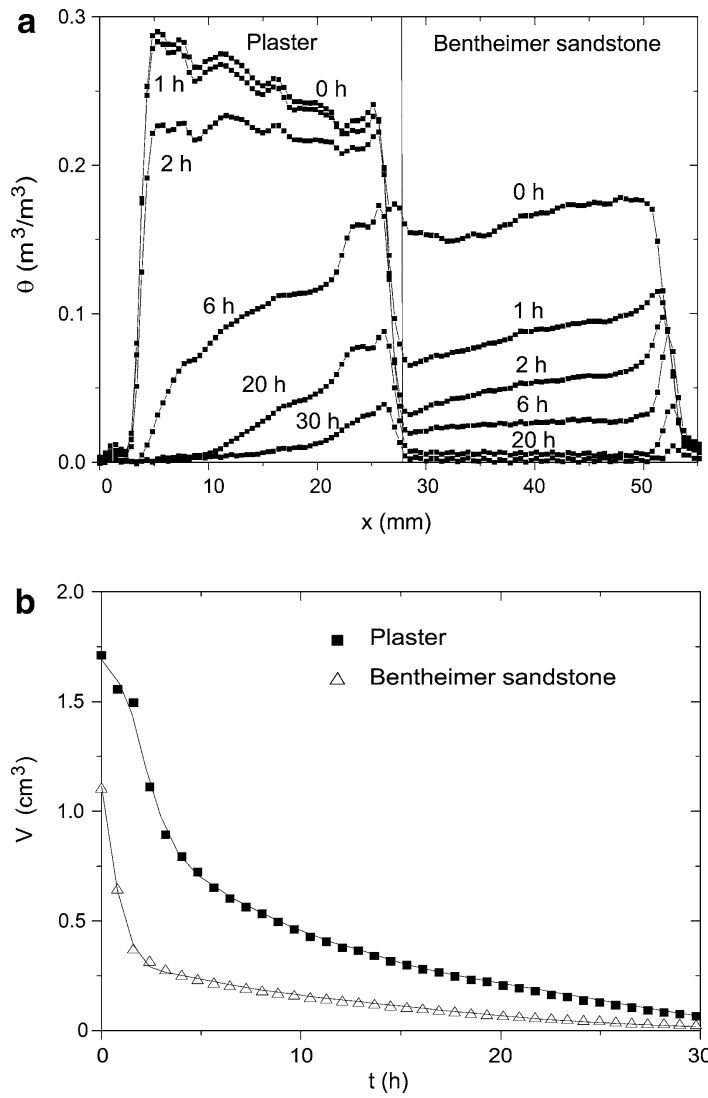

Fig. 4 (a) Moisture profiles in the plaster/Bentheimer sandstone system during drying. The sample was initially saturated with water. Dry air is blown over the top of the sample $(x=4 \mathrm{~mm})$ with a flow of $0.71 \mathrm{~min}^{-1}$. The maximum value of the moisture content $\Theta$ equals the (local) porosity of the system. (b) Total volumes of the water present in the plaster and Bentheimer sandstone as a function of the drying time

times during the drying process. The total amounts of water in the plaster and the Bentheimer sandstone as a function of drying time are shown in Fig. 5b. The initial water contents in both the sandstone and the substrate are somewhat lower than in the case of pure water, due to the presence of $4 \mathrm{~mol} \mathrm{l}^{-1}$ salt.

Similar to the case of pure water discussed above, two drying stages are observed. However, the drying of the salt loaded sample is much slower, which can be partly explained by the dependence of the drying rate on the relative humidity. The presence of salt decreases the relative humidity near the liquid/air interface and, consequently, decreases the drying rate $[28,29]$. It should be
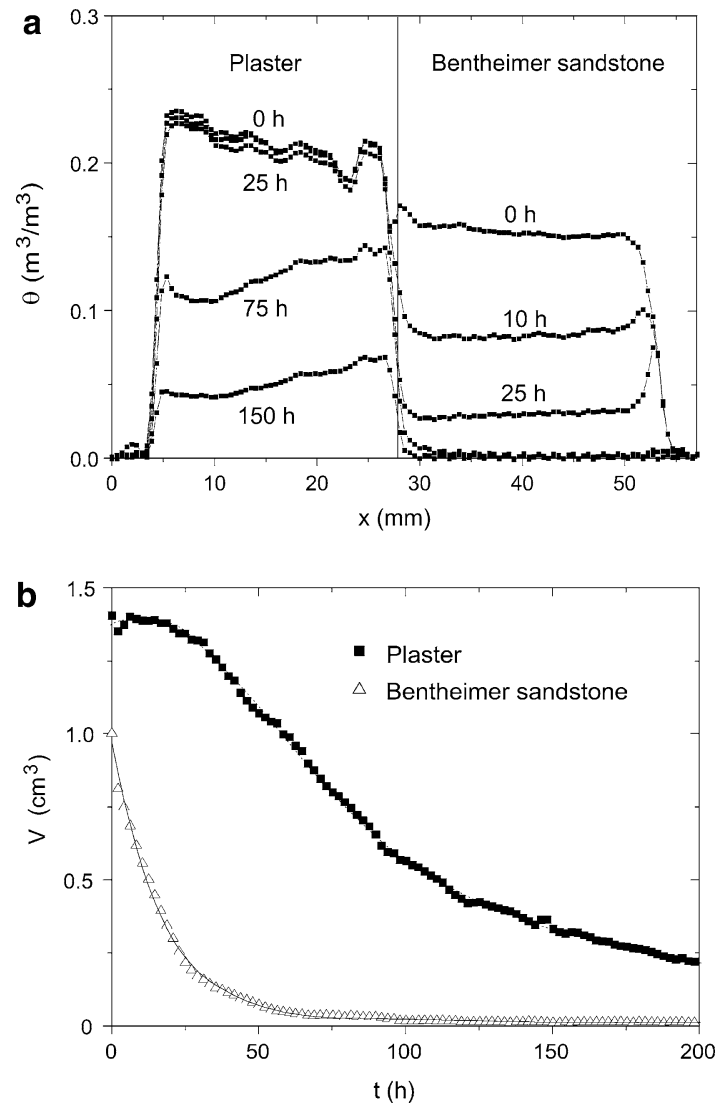

Fig. 5 (a) Moisture profiles in the plaster/Bentheimer sandstone system during drying. The sample was initially saturated with a $\mathrm{NaCl}$ solution $\left(c=4 \mathrm{~mol} \mathrm{l}^{-1}\right)$. Dry air is blown over the top of the sample $(x=4 \mathrm{~mm})$ with a flow of $0.71 \mathrm{~min}^{-1}$. (b) Total volumes of the water present in the plaster and Bentheimer sandstone as a function of the drying time

noted, however, that the decrease of the relative humidity near the liquid/air interface is smaller than a factor of 2 , and therefore cannot account for the observed decrease of the drying rate by a factor of 5-10. This is probably caused by (partial) blocking of the pores near the the drying surface by salt crystals, which reduces the effective surface area that is available for evaporation.

Apart from this, in the presence of salt no receding drying front is observed (Fig. 5a). This might be caused by a change in the wetting properties in the presence of $\mathrm{NaCl}$ [27]. This change may be related to the decrease of the contact angle $\phi$ between the liquid/air and the solid/liquid interface in the presence of salt [30]. In such a case, liquid films may be present and the 
liquid network will be complete until very low saturations.

In Fig. 6a the $\mathrm{Na}$ profiles are presented for several times during the drying process. The total amounts of dissolved $\mathrm{Na}$ in the plaster and the Bentheimer sandstone as a function of the drying time are shown in Fig. 6b. In the Bentheimer sandstone there appears to be no $\mathrm{Na}$ signal loss, and the amount of dissolved $\mathrm{Na}$ is measured quantitatively. The $\mathrm{Na}$ concentration can be calculated from the $\mathrm{Na}$ and water quantities. In the plaster not all $\mathrm{Na}$ can be measured, due to the fast transverse $\left(T_{2}\right)$ relaxation of $\mathrm{Na}$ in the small pores [31]. This signal loss in the plaster can be roughly corrected for by multiplying the measured signal with a correction factor $f$ :
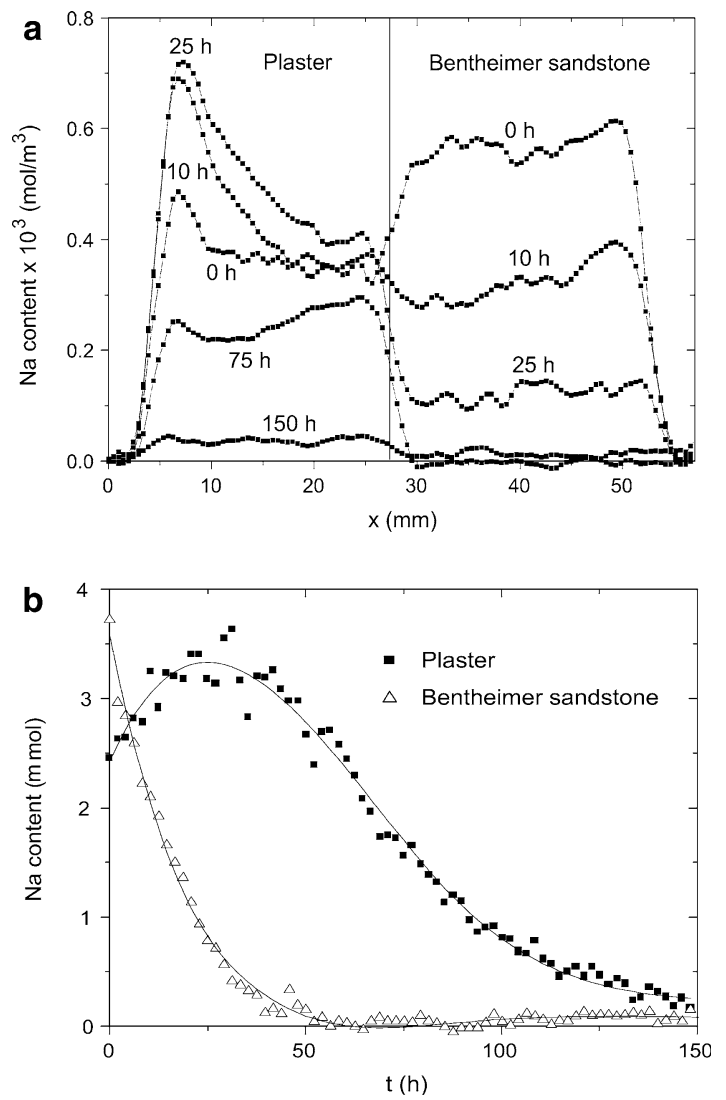

Fig. 6 (a) Profiles of dissolved $\mathrm{Na}$ in the plaster/ Bentheimer sandstone system. The data were recorded during the same drying experiment as that presented in Fig. 5. (b) Total amounts of dissolved $\mathrm{Na}$ ions in the plaster and Bentheimer sandstone as a function of the drying time $f=\frac{c_{0}}{c_{0, \mathrm{NMR}}}$

In this equation $c_{0}$ and $c_{0, \mathrm{NMR}}$ are the initial $\mathrm{Na}$ concentrations that are actually present and measured by NMR, respectively. It is assumed that the transverse relaxation rate of $\mathrm{Na}$ does not change with moisture content. Of course this is a rather crude approximation, that obviously does not hold when the moisture content in the plaster has decreased to less than about $20 \%$ of the saturation value. At lower moisture contents, only the smallest pores are filled with $\mathrm{NaCl}$ solution (see Fig. 3a), which leads to a drastic decrease of $T_{2}$ and hence the NMR signal intensity.

Inspection of Fig. 6 shows that during the first drying stage $(t<25 \mathrm{~h})$ the $\mathrm{Na}$ in the Bentheimer sandstone remains uniformly distributed, while the total amount of dissolved $\mathrm{Na}$ in the system decreases. The calculated Na concentration in the Bentheimer sandstone does not exceed the initial concentration of $4 \mathrm{~mol} \mathrm{l}^{-1}$. The amount of dissolved $\mathrm{Na}$ in the plaster increases during the first $25 \mathrm{~h}$ of drying. The resulting salt distribution in the plaster is not uniform, but a Na peak develops at the drying surface, see Fig. 6a. Correcting for the signal loss of the $\mathrm{Na}$ in the plaster, the estimated $\mathrm{Na}$ concentration at the top of the plaster after $25 \mathrm{~h}$ of drying is $6 \mathrm{~mol} \mathrm{l}^{-1}$, which is around the solubility limit of $\mathrm{NaCl}$. At this stage, crystallization at the air/plaster interface is visually observed.

These results indicate that diffusion plays a minor role in this stage of the drying process. This is confirmed by the velocity profiles that are calculated from the experimentally observed moisture profiles. In Fig. 7 the absolute value of the water velocity multiplied by the thickness of the plaster layer $|U| \cdot L$ is shown as a function of the position for several drying times. The horizontal line indicates the situation where $|U| \cdot L$ equals a diffusion constant of $10^{-9} \mathrm{~m}^{2} \mathrm{~s}^{-1}$. This value is roughly equal to the bulk diffusion constant of dissolved $\mathrm{Na}$ [32]. It follows from Eq. 2 that above this line $|U| \cdot L>D(P e>1)$, in which case advection dominates and ions are transported to the drying surface. Below the line $|U| \cdot L<D(P e<1)$ : diffusion transport domi- 


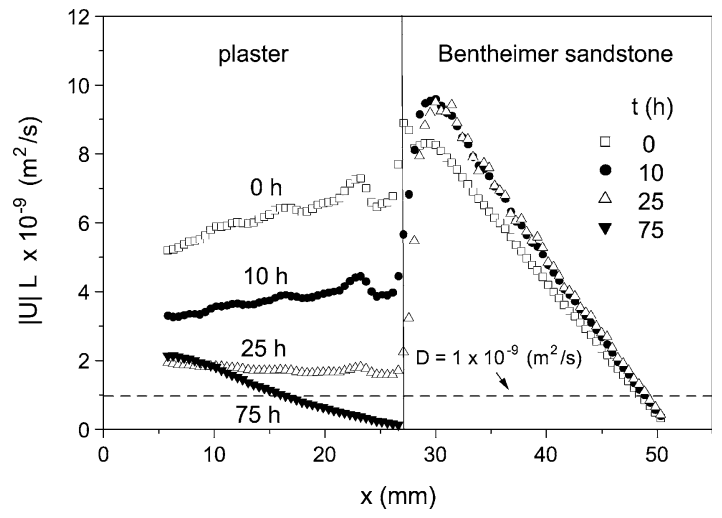

Fig. 7 Water velocity multiplied by the thickness of the plaster layer, $|U| \cdot L$, as a function of the position in the sample for several times during the drying process of a plaster/Bentheimer sandstone system. The horizontal line indicates the situation where $|U| \cdot L$ equals a diffusion constant of $10^{-9} \mathrm{~m}^{2} \mathrm{~s}^{-1}$, i.e., $P e=1$

nates and ions tend to be uniformly distributed within the various layers of the sample.

During the first drying stage $(t<25 \mathrm{~h})|U| \cdot L$ in the plaster decreases but does not vary much with $x$, since the water is distributed rather uniformly and $\theta$ is constant in time. During this stage the plaster acts only as a transport medium for moisture and ions from the Bentheimer sandstone to the drying surface. This is supported by the fact that the drying rate in the present system is almost the same as the drying rate of a Bentheimer sandstone substrate without plaster at the same experimental conditions. During this stage, $|U| \cdot L$ always exceeds $D$, which indicates that advection dominates. Ions that are present in or transported to the plaster layer will never be able to diffuse back to the Bentheimer sandstone. Therefore all salt will crystallize within the plaster. During the second drying stage $(t>25 \mathrm{~h})$ the Bentheimer sandstone is rather dry and the plaster starts to dry. The salt that is present in the plaster will crystallize and, therefore, the amount of dissolved Na decreases.

Our NMR results suggest that salt mainly accumulates and crystallizes in the plaster layer. To validate this, a sample was cut in eight slices after the drying process and the total amounts of $\mathrm{Na}$ and $\mathrm{Cl}$ of these slices were measured quantitatively by ion chromatography. Figure 8 shows the amount of $\mathrm{Na}$ in each slice. These $\mathrm{Na}$ contents

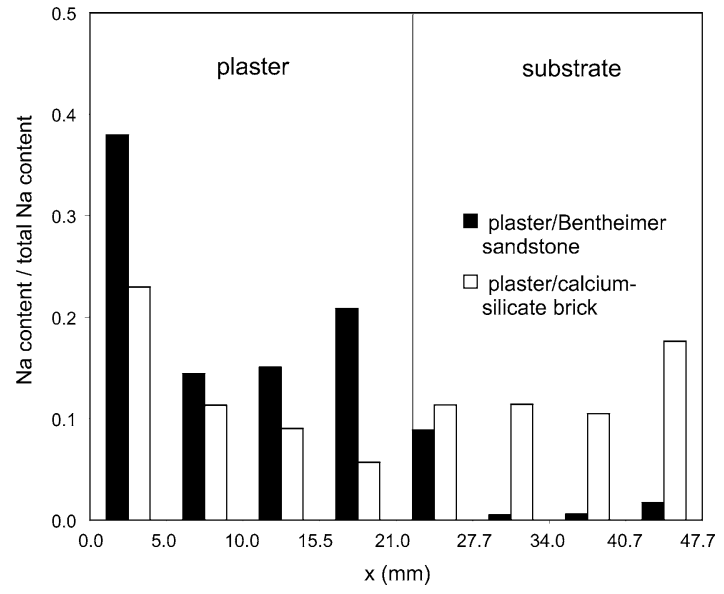

Fig. 8 Amount of $\mathrm{Na}$ in eight slices of a plaster/Bentheimer sandstone sample and a plaster/calcium-silicate brick sample determined by ion chromatography. The data are normalized to the total amount of $\mathrm{Na}$ in the respective samples

have been divided by the total amount of $\mathrm{Na}$ ions in the sample, i.e., the summed contents of all slices. The vertical line indicates the interface between the plaster and Bentheimer sandstone. The $\mathrm{Cl}$ distribution, which is not shown in the figure, was found to match the $\mathrm{Na}$ distribution within experimental inacuracy, indicating that both types of ions are transported together. The ion chromatography results confirm the conclusions derived from the NMR measurements, in the sense that after drying almost all salt is present in the plaster layer.

The efficiency numbers for the salt transport from the Bentheimer sandstone to the plaster layer have been calculated from the ion chromatography and NMR data and were estimated from the pore-size distributions (Fig. 3a) and the moisture contents (Eq. 4). The results are presented in

Table 1 Efficiency numbers for salt transport from substrates to plasters calculated in different ways

\begin{tabular}{lll}
\hline & $\begin{array}{l}\text { Plaster/Bentheimer } \\
\text { sandstone }\end{array}$ & $\begin{array}{l}\text { Plaster/calcium-silicate } \\
\text { brick }\end{array}$ \\
\hline$\varepsilon$ & 0.9 & 0.2 \\
$\varepsilon^{\prime}$ & 1 & - \\
$\varepsilon_{\mathrm{W}}$ & 1 & $0.6 \pm 0.1$ \\
$\varepsilon^{\prime}{ }_{\mathrm{w}}$ & 1 & $0.5 \pm 0.1$ \\
$\varepsilon_{\mathrm{p}}^{\prime}$ & 1 & $0.7 \pm 0.1$ \\
\hline
\end{tabular}


Table 1. The actual efficiency $\varepsilon$ is obtained from the amounts of $\mathrm{Na}$ measured by ion chromatography, presented in Fig. 8. The amount of $\mathrm{Na}$ in the slice between 21 and $27.3 \mathrm{~mm}$ is attributed to the interface and is therefore not taken into account in the calculation of the amount of $\mathrm{Na}$ in the Bentheimer sandstone.

The efficiency number $\varepsilon^{\prime}$ calculated using the amounts of dissolved $\mathrm{Na}$, measured by NMR, equals 1. This efficiency number is in good agreement with the actual efficiency number $\varepsilon$. The efficiency number $\varepsilon_{\mathrm{w}}$, defined in Eq. 4 , is a good approximation of the actual value for $P e>1$, which holds for our experiments on the plaster/ Bentheimer sandstone system. Indeed the efficiency numbers $\varepsilon_{\mathrm{w}}$ and $\varepsilon_{\mathrm{w}}^{\prime}$ agree nicely with $\varepsilon$.

In practice it is very difficult or even impossible to identify the smallest pore in a certain material. Therefore, in the calculation of $\varepsilon_{\mathrm{p}}$, the radius of the smallest pores in the plaster is defined as the radius where the cumulative pore volume of the plaster has reached $95 \%$ of the total pore volume (Fig. 3). This corresponds to the situation where the moisture content in the plaster has decreased to $5 \%$ of its saturation value. This value may seem somewhat arbitrary, but at such a moisture content no percolating water network is present anymore, and no salt transport is possible.

The results presented in the left column of Table 1 all show that at the conditions used in our experiments, the efficiency of salt transport from the Bentheimer sandstone to the plaster is very good, which is clearly related to the characteristic differences in the pore-size distributions of these two materials (Fig. 3a).

\subsection{Plaster/calcium-silicate brick}

\subsubsection{Pure water}

The plaster/calcium-silicate brick sample is initially saturated with pure water. The water profiles in this system for several times during the drying process are plotted in Fig. 9a. The total amounts of water in the two layers of this system as a function of drying time are presented in Fig. 9b. In this system three drying stages are observed. During the first drying stage $(t<4 \mathrm{~h})$, both the calcium-silicate brick and the plaster dry
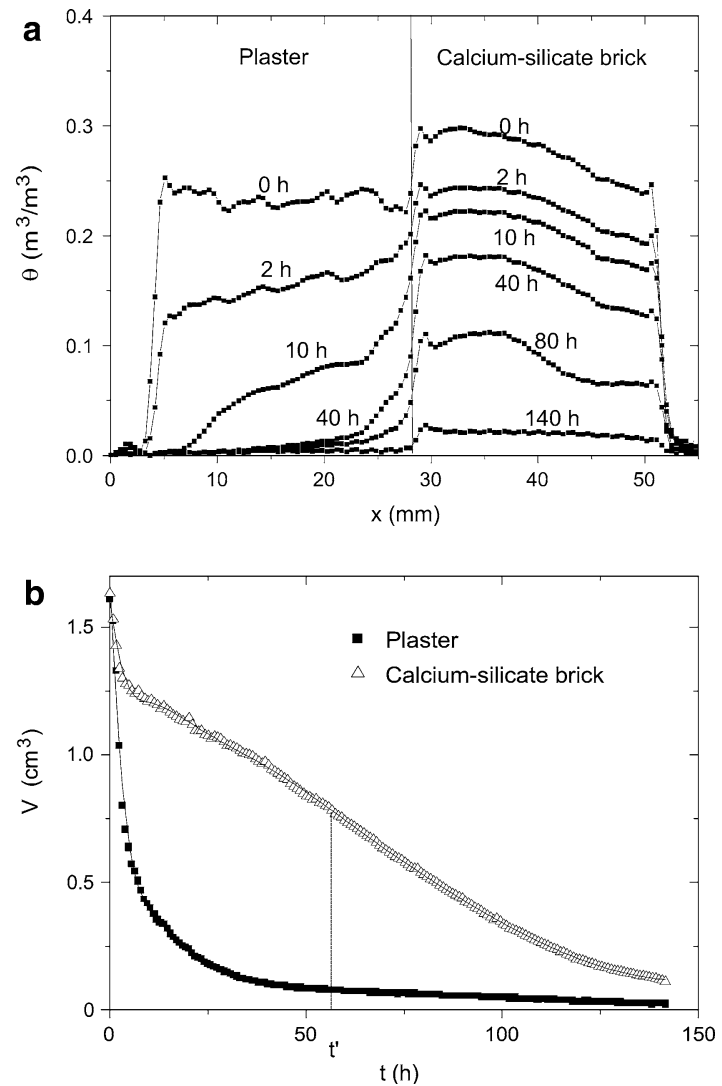

Fig. 9 (a) Moisture profiles in the plaster/calcium-silicate brick system during drying. The sample was initially saturated with water. The drying conditions were the same as in Fig. 5. (b) Total volumes of water present in the plaster and calcium-silicate brick as a function of the drying time. The time $t^{\prime}$ indicates the time at which the moisture content in the plaster has decreased to $5 \%$ of its saturation value

rapidly (Fig. 9b). During the second drying stage $(4-40 \mathrm{~h})$ the plaster continues to dry rapidly, whereas the drying of the calcium-silicate brick is much slower than during the first stage. During the third drying stage $(t>40 \mathrm{~h})$ the plaster is almost dry, and the calcium-silicate brick still contains a significant amount of water.

The drying behavior of the plaster/calcium-silicate brick system differs significantly from the drying of the plaster/Bentheimer sandstone system. This is a consequence of the different poresize distributions of both systems (see Fig. 3b). The drying again can be explained by the capillary pressure (Eq. 1). Air first invades the pores with the lowest capillary pressure, i.e., the widest 
pores. In the calcium-silicate brick two dominant pore sizes $(\sim 20 \mathrm{~nm}$ and $20 \mu \mathrm{m})$ are present. The first pore size is at least an order of magnitude smaller than the dominant pore size of the plaster $(\sim 1 \mu \mathrm{m})$, the second at least an order of magnitude larger. The volume of the nanometer pores of the calcium-silicate brick is significant and the presence of these pores has a large effect on the drying behavior of the plaster/calcium-silicate brick system. During the first drying stage, water evaporates from the largest pores in the brick and the plaster. During the second drying stage the largest pores in the calcium-silicate brick are empty, and now mainly the pores in the plaster are drying. During the third drying stage only the smallest pores of the calcium-silicate brick still contain water.

\subsubsection{Salt solution}

The sample was initially saturated with a $\mathrm{NaCl}$ solution, $c=4 \mathrm{~mol} \mathrm{l}^{-1}$. The water profiles are presented in Fig. 10a for several times during the drying process. The total amounts of water in the plaster and the calcium-silicate brick during drying are shown in Fig. 10b. Again, three drying stages can be distinguished, similar to the case of the pure water. The main influence of the salt is that the drying is much slower than in the case of pure water (Fig. 10) and that no receding drying front is present. Possible causes of these characteristics have already been discussed above.

In Fig. 11a, the Na profiles are plotted for several times during the drying process. The total amounts of dissolved $\mathrm{Na}$ in the plaster and the calcium-silicate brick during drying are shown in Fig. 11b. In this case the Na signal loss in both the plaster and calcium-silicate brick was corrected for according to the procedure outlined in section 4.1.

During the first drying stage $(t<12 \mathrm{~h})$ the amount of $\mathrm{Na}$ in the plaster stays constant within experimental accuracy, whereas the amount of $\mathrm{Na}$ in the calcium-silicate brick decreases. The velocity profiles calculated from the experimental moisture profiles are plotted in Fig. 12. This figure shows that, advection dominates during the first drying stage; in both materials $|U| \cdot L$ is larger than $D(P e>1)$, with the obvious exception of a small region near the sealed end of the sub- strate, where $U=0$. As a result, salt is transported from the calcium-silicate brick to plaster, where it accumulates near the drying surface.

During the second drying stage $(12-100 \mathrm{~h})$, the amount of dissolved $\mathrm{Na}$ in the plaster decreases. If we estimate the $\mathrm{NaCl}$ concentration in the plaster from the amounts of water and dissolved $\mathrm{Na}$, corrected for the signal loss, it has reached the solubility limit $\left(c=6 \mathrm{~mol} \mathrm{l}^{-1}\right)$, which implies that crystallization will occur in the plaster. At the same time the amount of dissolved $\mathrm{Na}$ in the calcium-silicate brick increases.

Because of the slower drying of the calciumsilicate brick the diffusive transport becomes more important [33]. This is confirmed by the
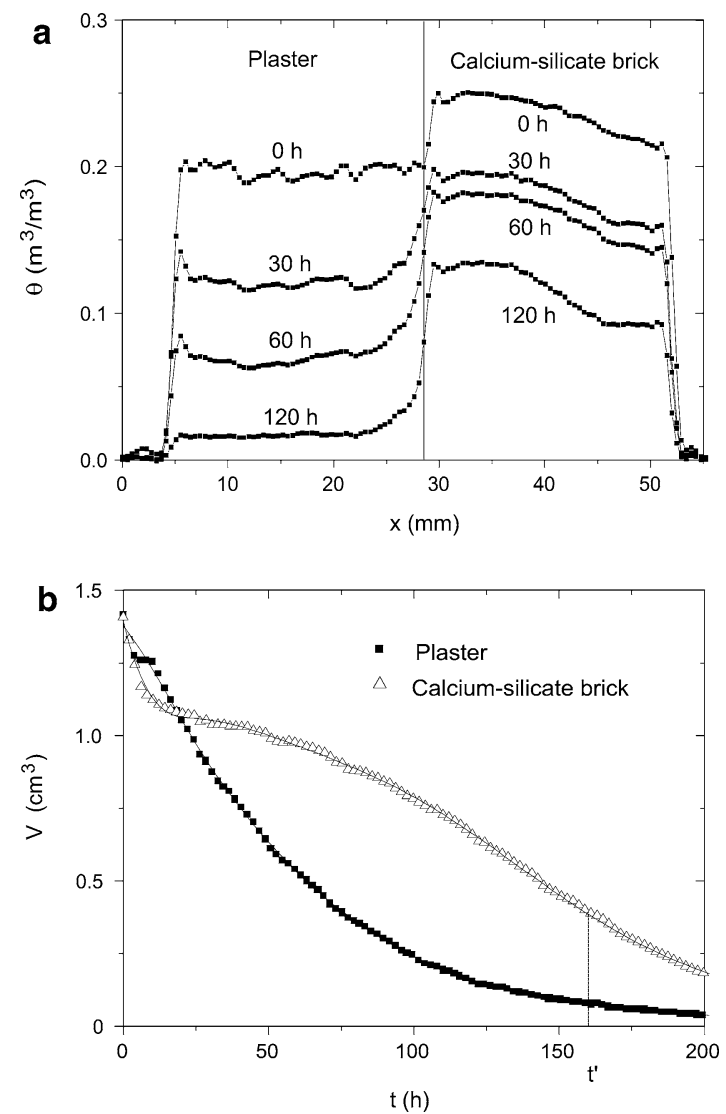

Fig. 10 (a) Moisture profiles in the plaster/calcium-silicate brick system during drying. The sample was initially saturated with a $\mathrm{NaCl}$ solution $\left(c=4 \mathrm{~mol} \mathrm{l}^{-1}\right)$. The drying conditions are the same as in Fig. 9. (b) Volume of water in the plaster and the calcium-silicate brick as a function of the drying time. The meaning of the time $t^{\prime}$ is explained in the text 
velocity profiles, plotted in Fig. 12. During this stage, $|U| \cdot L$ in calcium-silicate brick is lower than $D(P e<1)$ and diffusion dominates advection. Back diffusion and redistribution of the salt occurs and salt accumulates in the calcium-silicate brick. The amount of dissolved $\mathrm{Na}$ continues to increase until the moment that the solubility limit is reached and crystallization occurs. During the third drying stage $(t>100 \mathrm{~h})$ no dissolved $\mathrm{Na}$ is present in the plaster, because the plaster is essentially dry. The quantity of dissolved $\mathrm{Na}$ in calcium-silicate brick decreases due to crystallization.

The NMR results on the calcium-silicate brick system suggest that salt crystallizes everywhere in the sample. This was checked by ion chromatog-
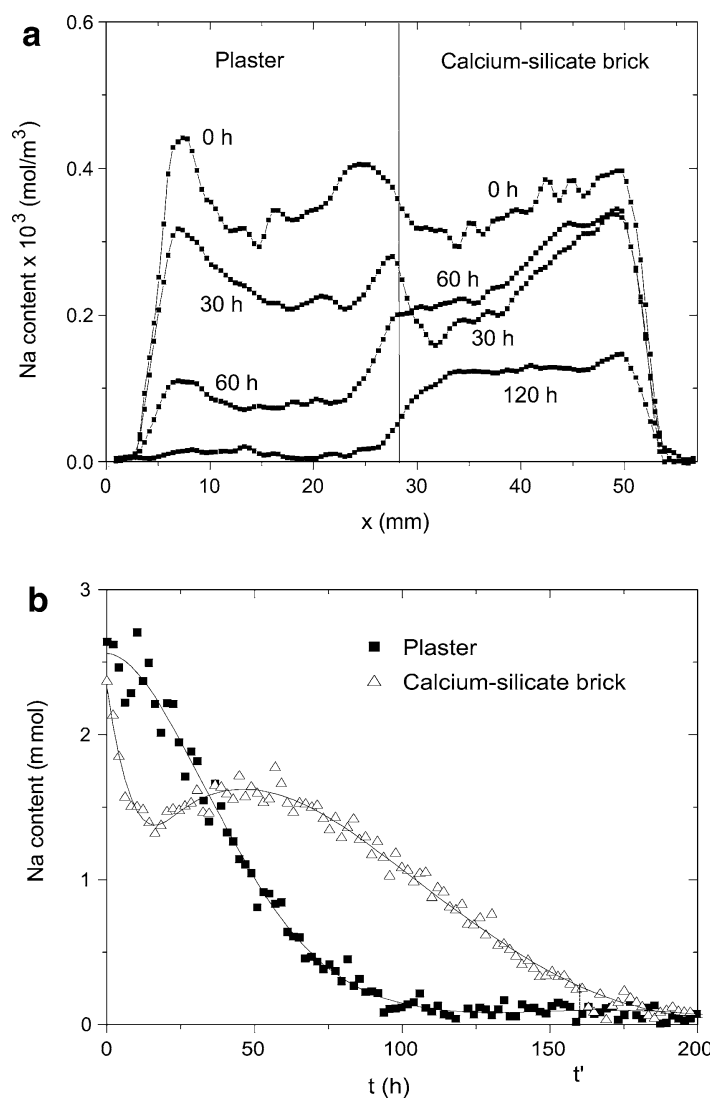

Fig. 11 (a) Profiles of dissolved $\mathrm{Na}$ in the plaster/ calciumsilicate brick system. The data were recorded during the same drying experiment as that presented in Fig. 10. (b) Total amounts of dissolved sodium ions in the plaster and the calcium-silicate brick as a function of the drying time. The meaning of the time $\mathrm{t}^{\prime}$ is explained in the text raphy. The results for the present system are included in Fig. 8. The measured $\mathrm{Cl}$ distribution was found to follow the $\mathrm{Na}$ distribution within experimental inaccuracy, which indicates that both ions are transported together. The salt has crystallized in the whole plaster/calcium-silicate brick sample, which confirms the conclusion drawn from the NMR experiment. Part of the salt has accumulated near the drying surface.

Some salt seems to have accumulated at the end of the calcium-silicate brick substrate, which suggest that drying also occurred at the back surface of the sample. In this respect one should note note that in the present experiment the drying of the substrate was very slow, in which case the unavoidable imperfections of the sealing of the back surface by the teflon tape may have a noticeable effect.

The efficiency numbers for the salt transport from the calcium-silicate brick to the plaster layer have been calculated from the ion chromatography and NMR data and were estimated from the pore-size distributions (Fig. 3) and the moisture contents (Eq. 4). The results are included in Table 1. The efficiency numbers are determined from the sodium or water amounts in the substrate at the time $t^{\prime}$ when the moisture content in the plaster has decreased to $5 \%$ of its saturation value. As mentioned in Sect. 4.1, it is assumed that below this moisture content no further

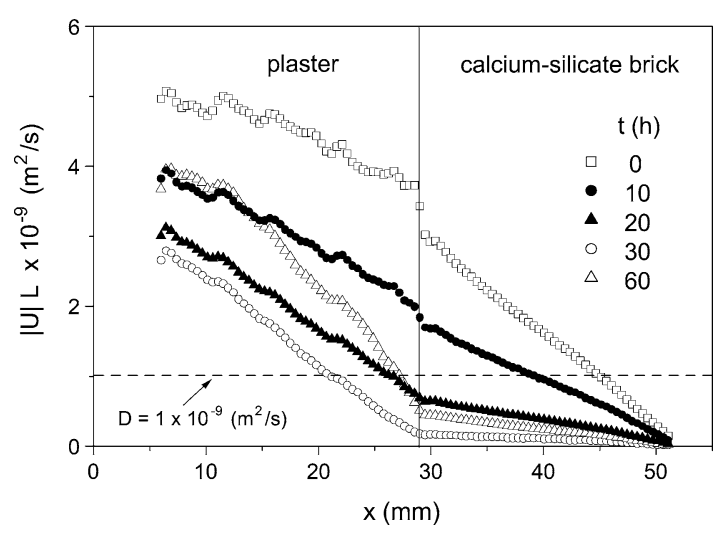

Fig. 12 Water velocity multiplied by the length of the plaster layer, $|U| \cdot L$, as a function of the position in the sample for several times during the drying process of a plaster/calcium-silicate brick system. The horizontal line indicates the situation where $|U| \cdot L$ equals a diffusion constant of $10^{-9} \mathrm{~m}^{2} \mathrm{~s}^{-1}$, i.e., $P e=1$ 
transport of salt is possible. These times are indicated by the vertical dashed lines in the Figs $9 b-11 b$. The error margins in the right column of table 1 reflect the uncertainty in the determination of the time $t^{\prime}$. One should note that at the start of our experiments not all pores are filled with fluid, since we start from capillary saturation. Consequently, the time $t^{\prime}$ corresponds to a situation where the moisture most likely occupies less than $5 \%$ of the total pore volume measured by mercury intrusion porosimetry. Hence the present estimates of the efficiency number using Eq. 4 should be considered as upper limits.

The actual efficiency number $\varepsilon$, obtained from the total $\mathrm{Na}$ amount measured by ion chromatography, amounts to 0.2. From the $\mathrm{Na}$ amounts measured by NMR no reliable value of the efficiency number $\varepsilon^{\prime}$ can be calculated. As the drying in this system proceeds, not only dissolved $\mathrm{Na}$ is present in the calcium-silicate brick, but also $\mathrm{Na}$ has crystallized. Only dissolved $\mathrm{Na}$ is measured by $\mathrm{NMR}$, and therefore the total amount of $\mathrm{Na}$ that remains in the substrate will be underestimated. Since in the plaster/ calcium-silicate brick system the condition $P e>1$ does not hold during a large part of the drying process, the efficiency numbers estimated from the water quantities in both layers or from the pore-size distributions, such as $\varepsilon_{\mathrm{w}}$ and $\varepsilon_{\mathrm{p}}$, should only be regarded as crude estimates of the efficiency of salt transport.

Generally, the efficiency of salt transport from the calcium-silicate brick to the plaster is poor, in contrast to that of the plaster/Bentheimer sandstone system. This difference is a direct consequence of the nanometer pores that are present in the calcium-silicate brick. During the last part of the drying process, when the large pores of the calcium-silicate brick and the plaster layer are dry, water and salt are still present in these nanometer pores.

\section{Non-uniformly salt loaded sytems}

Until now we have investigated the salt and moisture transport in plaster/substrate systems which are uniformly salt loaded. In reality, the initial salt distribution might be inhomogeneous, depending on the salt and water sources in the system. In order to investigate the effect of a nonuniform initial salt distribution, we have studied the transport in a plaster/Bentheimer sandstone sample of which the plaster layer is immersed in pure water for several seconds and the Bentheimer sandstone is immersed in a $\mathrm{NaCl}$ solution $\left(c=4 \mathrm{~mol} \mathrm{l}^{-1}\right)$.

Water profiles of this sample for several times during the drying process are plotted in Fig. 13a. The total amounts of water in the plaster and the Bentheimer sandstone as a function of drying time are shown in Fig. 13b. In Fig. 14a the Na profiles are presented for several times during the
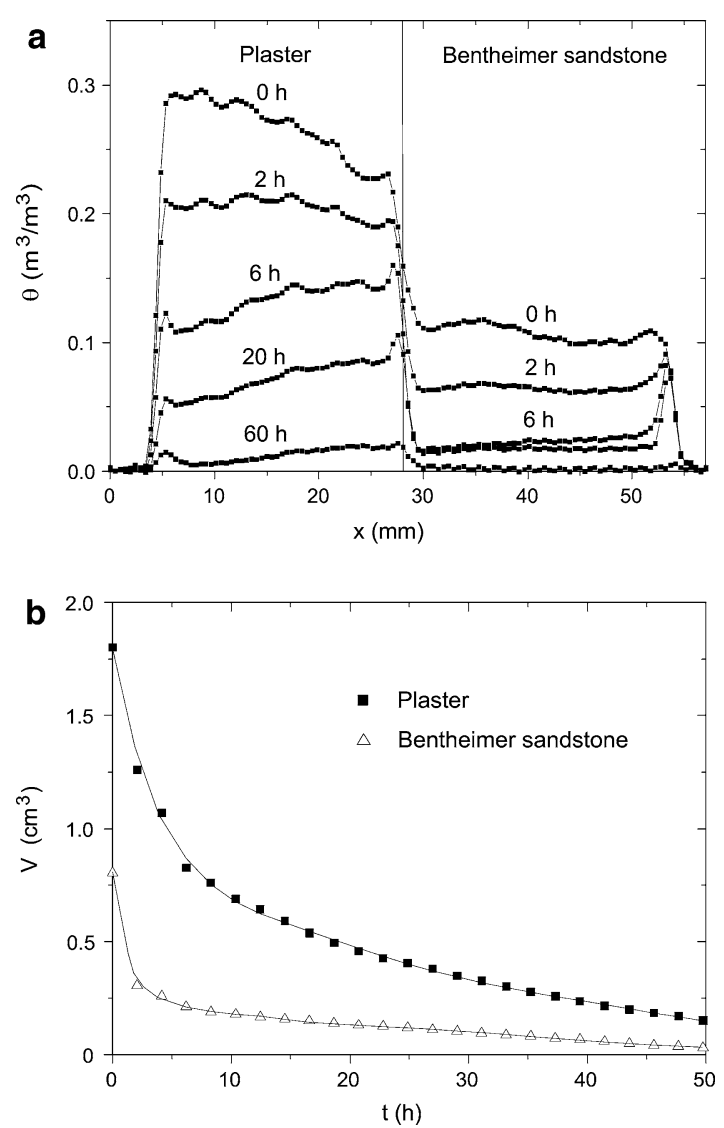

Fig. 13 (a) Moisture profiles in the non-uniformly salt loaded plaster/Bentheimer sandstone system for different times during the drying process. The plaster was initially saturated with pure water and the Bentheimer sandstone was saturated with a $\mathrm{NaCl}$ solution $\left(c=4 \mathrm{~mol} \mathrm{l}^{-1}\right)$. The drying conditions are the same as in Fig. 5. (b) Total volumes of water present in the plaster and the Bentheimer sandstone as a function of the drying time 
drying process. The total amounts of dissolved $\mathrm{Na}$ in the plaster and the Bentheimer sandstone as a function of the drying time are shown in Fig. 14b.

Since the plaster layer is now saturated with pure water, the drying of this sample is much faster than that of the uniformly salt loaded sample, described in Sect. 4.1. The salt transport is completely different, since in this case the initial salt content of the plaster layer is zero. Figure 14 shows that salt is transported to the drying surface, and the total amount of salt in the plaster layers increases.

The velocity profiles plotted in Fig. 15 indicate that the salt is transported by advection, since $|U| \cdot L>D$. Most of the salt is already transported to the plaster within the first $10 \mathrm{~h}$ of
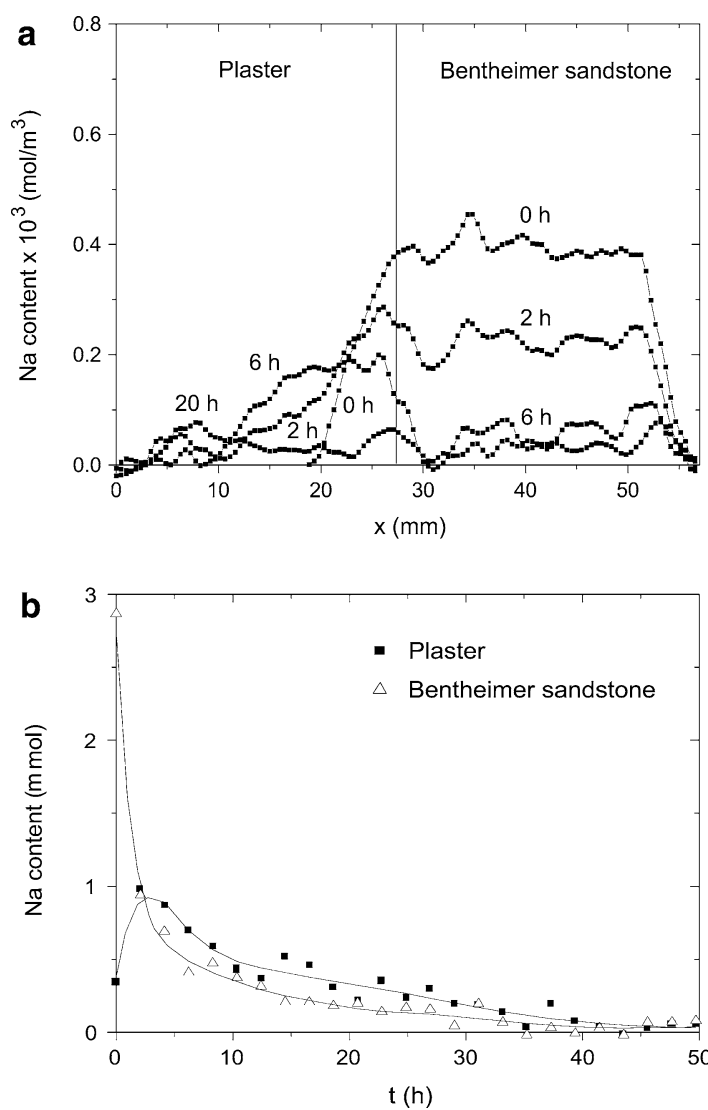

Fig. 14 (a) Profiles of dissolved $\mathrm{Na}$ in the non-uniformly salt loaded plaster/Bentheimer sandstone system. The data were recorded during the same drying experiment as that presented in Fig. 13. (b) Total amounts of dissolved sodium in the plaster and the Bentheimer sandstone as a function of the drying time

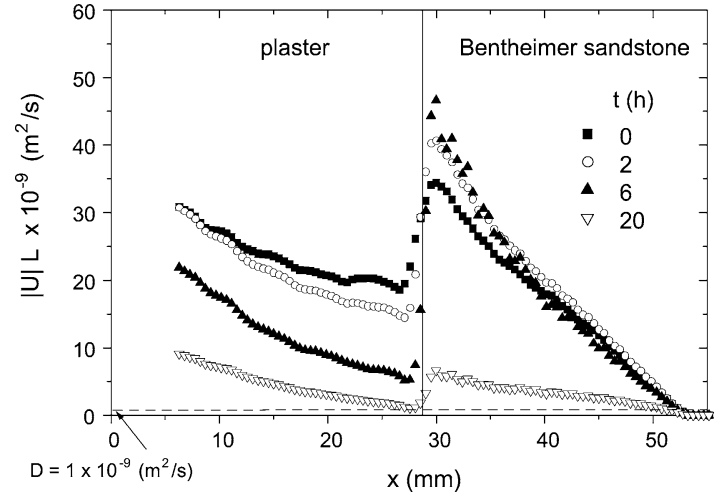

Fig. 15 The water velocity multiplied by the thickness of the plaster layer $(|U| \cdot L)$ versus the position in the sample for several times during the drying process of a nonuniformly salt loaded plaster/Bentheimer sandstone system. The horizontal line indicates the situation where $|U| \cdot L$ equals a diffusion constant of $10^{-9} \mathrm{~m}^{2} \mathrm{~s}^{-1}$, i.e., $P e=1$

the drying process. After $50 \mathrm{~h}$ the Bentheimer sandstone is dry. The NMR results suggest that all salt is transported to the plaster. This indicates that the efficiency of the salt transport from the Bentheimer sandstone to the plaster equals 1 , similar to the uniformly salt loaded sample (Sect. 4.1).

To validate this, the sample was cut in nine slices after the drying experiment and the total amount of $\mathrm{Na}$ in these slices was measured quantitatively by ion chromatography. Figure 16 shows the amount of $\mathrm{Na}$ in each slice. These $\mathrm{Na}$ contents have been divided by the total amount of

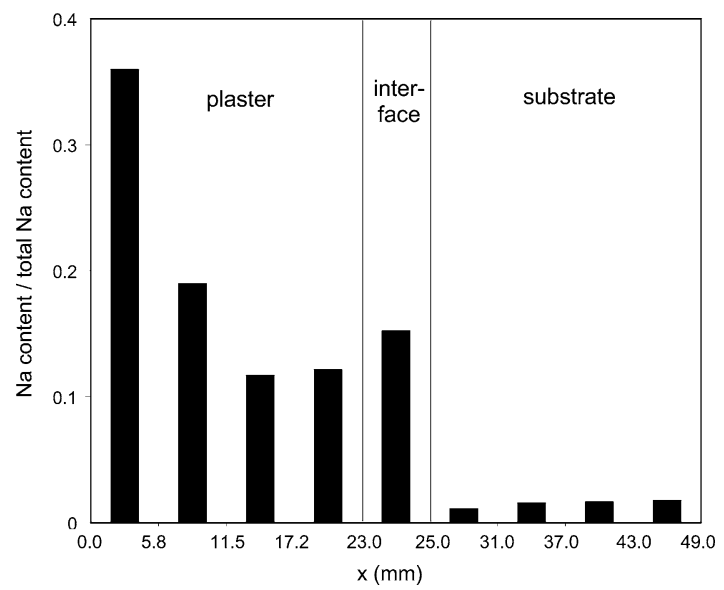

Fig. 16 Normalized Na content in the non-uniformly salt loaded plaster/Bentheimer sandstone system as a function of position 
$\mathrm{Na}$ ions in the sample, i.e., the summed contents of all slices. This figure shows that the almost all salt is present in the plaster layer and in the interface layer, which confirms the results obtained by NMR. The overall salt distribution resembles the salt distribution obtained by ion chromatography for the uniformly salt loaded plaster/Bentheimer sandstone system, which is plotted in Fig. 8.

\section{Conclusions}

Our drying experiments demonstrate that the same plaster applied on a different substrate may have a different drying behavior. This can be explained by differences in the pore sizes between the plaster and the substrate. The layer with the largest pores dries first. Therefore, the drying behavior of a plaster/substrate system depends on the pore-size distributions of both the plaster and the substrate.

Measurements on salt loaded systems indicate that the salt transport and accumulation is determined by drying behavior of the plaster/substrate system and, therefore, by the pore sizes of both the plaster and the substrate. When the plaster has small pores compared to the substrate (plaster/ Bentheimer sandstone system), the salt accumulates in the plaster for all drying rates. On the other hand, when the plaster has larger pores than the substrate, like the plaster/calcium-silicate brick system, a significant amount of salt will crystallize within the substrate itself. When the drying rate is low, we expect that hardly any salt will crystallize in the plaster. At high drying rates, advection dominates the ion transport and salt will crystallize in both the plaster and the substrate.

The drying of the plaster/Bentheimer system of which the substrate was saturated with a salt solution and the plaster was saturated with pure water is very fast compared to the system that was uniformly saturated with a salt solution. At the drying conditions used in the present study (air speed over the drying surface of the order of $0.1 \mathrm{~m} / \mathrm{s}$ and a very low relative humidity) advection dominates. The salt is transported to the plaster and accumulates there.
We have seen that the salt transport is determined by the Péclet number $P e$, which can be calculated from the drying rate. In practice a lot of factors are influencing the drying rate and, correspondingly, the salt transport and accumulation. With increasing external temperature or air speed or with decreasing relative humidity of the environment, the drying rate increases, which results in increase of $P e$.

We have introduced an efficiency number $\varepsilon$, which is a measure of the efficiency of salt transport from the substrate to the plaster. It is a simple, practical number, which can be estimated without performing actual measurements of moisture or salt transport. The efficiency number, estimated in various ways, shows that the efficiency of salt transport from the Bentheimer sandstone to the plaster is very good, whereas the efficiency of salt transport from calcium-silicate brick to the same plaster is poor. Even without knowing the salt or water quantities in the plaster and the substrate, it is possible to obtain an estimate of $\varepsilon_{\mathrm{p}}$ using the cumulative pore-size distributions of the two materials. Therefore, it is possible to estimate the efficiency number $\varepsilon_{\mathrm{p}}$ before the materials are in physical contact.

Concluding we like to note that all estimates for the efficiency number $\varepsilon_{\mathrm{p}}$ are based on various assumptions, such as that the materials are in the perfect hydraulic contact and that the drying is sufficiently fast, i.e., $P e \gg 1$. Moreover, we have assumed that no microcracks have been formed in the plaster during carbonation. The NMR signal decay of water present in these microcracks would be very slow compared to that of water present in the pores itself. Such a contibution to the NMR signal decay has not been observed, indicating that - if microcracks are actually present - their amount is very small. In the case of slow drying $\varepsilon_{\mathrm{p}}$ can only be regarded as crude approximation of the efficiency of salt transport. In composite materials which consist of more than two layers, the simple model that we used to estimate the efficiency number $\varepsilon_{\mathrm{p}}$ may not be correct, and a non-invasive technique like NMR is necessary to investigate the moisture and salt transport in these materials during the drying process. 
Acknowledgements Part of this research was supported by the Dutch Technology Foundation (STW), the Priority Program Materials Research (PPM), the Center for Building and Systems TNO-TUE, and the EU Directorate General Research

\section{References}

1. Wijffels TJ, Groot CJWP, van Hees RPJ (1997) Performance of restoration plasters. 11th International Brick/Block Masonry Conference, Shanghai, China, pp 1050-1062

2. Lubelli B, van Hees RPJ, Groot CJWP (2005) The performance of a restoration plaster in the field: investigation and monitoring of two case studies. International Workshop: repair mortars for historic masonry. Delft, The Netherlands

3. Goudie A, Viles H (1997) Salt weathering hazard. Wiley, Chichester

4. Dullien FAL (1991) Porous media: fluid transport and pore structure. Academic Press, London

5. Reinhardt HW, Gaber K (1990) From pore size distribution to equivalent pore size of cement mortar. Mater Struct 23:3-15

6. Nuame BK, Illston JM (1981) Relationships between permeability and pore structure of haredened cement pastes. Mag Concr Res 33:139-146

7. Mehta PK, Manmohan D (1980) Pore distribution and permeability of hardened cement pastes. 7 th International Symposium of the Chemistry of Cement, Paris France

8. El Dieb AS, Hooton RD (1994) Evaluation of the Katz-Thomson model for estimating the water permeability of cement based materials from mercury intrusion porosimetry data. Cem Concr Res 24:443-455

9. Garboczi EJ (1990) Permeability, diffusivity and microstructural parameters: a critical rewiew. Cem Concr Res 20:591-601

10. Quenard DA, Xu K, Kuenzel HM, Bentz DP, Martys NS (1998) Microstructure and transport properties of porous building materials. Mater Struct 31:317-324

11. Bear J, Bachmat Y (1990) Introduction to modeling of transport phenomena in porous media, Vol 4. Kluwer, Dordrecht, The Netherlands

12. Robinson GC (1984) The relationship between pore structure and durability of brick. Bull Am Ceram Soc 63:295-300

13. Lubelli B, van Hees RPJ, Larbi J (2004) Influence of brick properties on salt crystalization damage. 6th International symposium on the conservation of monuments in the Mediteranean basin, Lisbon, Portugal, pp 283-288

14. Rossi-Manaresi R, Tucci A (1991) Pore structure and the disruptive or cementing effect of salt crystallization in various types of stone. Stud Conserv 36:56-58
15. WTA Merkblatt 2-2-91 (1992) Sanierputzsysteme, Wissenschaftlich technischen Arbeitsgemeinschaft für Bauwerkserhaltung und Denkmalpflege

16. Brocken HJP, Pel L (1997) Moisture transport over the brick-mortar interface: water absorption and drying. 11th International Brick/Block Masonry Conference, Shanghai, China, pp 826-835

17. Brocken HJP (1998) Moisture transport in brick masonry: the grey area between bricks. PhD Thesis, Eindhoven University of Technology

18. van Brakel J (1980) Mass transfer in convective drying, 'Advances in drying', Vol 1. Hemisphere, Washington

19. Le Bray Y, Prat M (1999) Three dimensional pore network simulation of drying in capillary porous media. Int J Heat and Mass Trans 42:4207-4224

20. Pel L, Huinink HP, Kopinga K (2002) Ion transport and crystallization in inorganic building materials as studied by nuclear magnetic resonance. Appl Phys Lett 81:2893-2895

21. Kopinga K, Pel L (1994) One-dimensional scanning of moisture in porous materials with NMR. Rev Sci Instrum 65:3673-3681

22. Pel L (1995) Moisture Transport in Porous Building Materials. PhD Thesis, Eindhoven University of Technology

23. Pel L, Kopinga K, Kaasschieter EF (2000) Saline absorption in calcium-silicate brick observed by NMR scanning. J Phys D: Appl Phys 33:1380-1385

24. Callagan PT (1991) Principles of nuclear magnetic resonance microscopy. Clarendon Press, Oxford

25. Brownstein KR, Tarr CE (1979) Importance of classical diffusion in NMR studies of water in biological cells. Phys Rev A 19:2446-2452

26. Valckenborg RME, Pel L, Kopinga K (2001) NMR relaxation and diffusion measurements on iron (III) doped kaolin clay. J Magn Res 151:291-297

27. Pel L, Huinink HP, Kopinga K (2003) Salt transport and crystallization in porous building materials. Magn Reson Imaging 21:317-320

28. Hall C, Hoff WD (2002) Water transport in brick, stone and concrete. Spon, London

29. Daïan JF (2002) Coupled salt and moisture transport in partially saturated porous media, in Poromechanics II Proceedings of the second Biot Conference on Poromechanics. Grenoble, France, pp 407-412

30. Nijland T (2004) Private communication

31. Rijniers LA (2004) Salt crystallization in porous materials: an NMR study. PhD Thesis, Eindhoven University of Technology

32. Mills R, Lobo VMM (1989) Self diffusion in electrolyte solutions in 'Physical Sciences Data', Vol 36. Elsevier

33. Pel L, Huinink HP, Kopinga K, van Hees RPJ, Adan OCG (2004) Efflorescence pathway diagram: understanding salt weathering. Constr Build Mater 18:309313 